\title{
An Embedded Systems Perspective in Conceptualizing Canada's Healthcare Sustainability
}

\author{
Peter Tsasis ${ }^{1, *}$, Nirupama Agrawal ${ }^{2}$ (D) and Natalie Guriel ${ }^{2}$ \\ 1 Faculty of Health and Environmental Studies, York University, Toronto, ON M3J 1P3, Canada; \\ tsasis@yorku.ca \\ 2 Faculty of Liberal Arts and Professional Studies, York University, Toronto, ON M3J 1P3, Canada; \\ nirupama@yorku.ca (N.A.); nguriel@yorku.ca (N.G.) \\ * Correspondence: tsasis@yorku.ca
}

Received: 10 December 2018; Accepted: 17 January 2019; Published: 20 January 2019

\begin{abstract}
Healthcare sustainability has been dominated by a strong fiscal orientation. In an era of budget cuts and staff reductions, the financial challenges in Canadian healthcare are immediate and must be addressed. However, an independent focus on financial viability is too narrow a framing; too limited to allow for the kind of creative, novel, and even radical thinking that is required to fundamentally alter the current course of healthcare in Canada and internationally. Prospects for solving the current financial challenges are likely to be greatly enhanced if we simultaneously account for the broad and interrelated dimensions of sustainability. What would a healthcare system look like if sustainability were adopted as the focal and principal goal? And what might a "deep" sustainability orientation imply for how we think about and manage healthcare systems? This analysis is informed by the notion that healthcare systems are fully contained within the societal system, which is itself fully contained within the broader ecological system. This model, which foregrounds nature as the most fundamental and important system, has both greater ecological validity and particular relevance to the healthcare context given the interdependence between the health of natural systems and the health of humans. Our understanding of nature in relation to health may be key to solving or at least reducing the economic burden of healthcare. A multidimensional systems orientation thus has the potential to unveil new modes of thinking that highlight intersectoral relations, communications, collaboration, and cross-boundary learning for improved health and wellbeing, healthcare performance, and sustainability.
\end{abstract}

Keywords: Canadian healthcare system; sustainability; Canada; systems learning; risk-based

\section{Introduction}

The concept of sustainability is now at the fore of social consciousness and permeates discussions across the private, public, and what Mintzberg [1] has coined the "plural" sector. The domain of healthcare is no exception and with good reason. Health is the most basic element underpinning a functioning society, and sustaining health and healthcare is, by definition, existentially critical for social welfare and continuity. However, healthcare systems around the world and throughout Canada in particular, are under enormous social and financial pressures such that the continued viability of existing healthcare models appears highly uncertain.

The recognized importance of healthcare-reflected in the public's ever-increasing expectations for accessible, timely, and effective care-coupled with limited, and in many cases diminishing financial resources, has meant that discussions regarding healthcare sustainability have been dominated by a strong fiscal orientation. Clearly, in an era of budget cuts, staff reductions, and other substantive frontline service impacts, the financial challenges in Canadian healthcare are immediate and must 
be addressed. However, we believe a singular focus on financial viability is at once too narrow a framing for the sustainability concept itself, and more importantly, too limited to allow for the kind of creative, novel, and even radical thinking that is required to fundamentally alter the current course of healthcare in this country. In our view, prospects for solving even the current financial challenges are likely to be greatly enhanced if we simultaneously account for the broad and interrelated dimensions of sustainability.

Although the so-called three pillars model of sustainability [2], comprised of economic, social, and environmental facets, has received widespread acceptance in many areas, only recently have health scholars attempted to use this holistic framework as a basis for conceptualizing sustainable healthcare [3]. Given the nascent status of these efforts, we see considerable opportunity to advance ideas about what sustainability thinking implies for healthcare, and further, to consider how healthcare might lead efforts towards sustainability. In this conceptual paper we seek to push the boundaries of the sustainable healthcare discussion and ask: How can healthcare contribute to human flourishing? [4] What would a healthcare system look like if sustainability were adopted as the focal and principal goal, and what might a "deep" sustainability orientation imply for how we think about and manage healthcare systems?

In contrast to dominant sustainability conceptions and those previously applied to the health domain, our analysis is informed by an embedded view-the notion that healthcare systems are fully contained within the societal system, which is itself fully contained within the broader ecological system [5]. We believe this model, which foregrounds nature as the most fundamental and subsequently most important system, has both greater ecological validity and particular relevance to the healthcare context given the inextricable links between the health of natural systems and the health of humans. For example, environmental degradation, air pollution, and climate change can result in flooding, insect borne diseases, droughts and wildfires; all posing existential risks to health. Furthermore, there is a growing body of evidence to suggest that our understanding of nature in relation to health may be key to solving or at least reducing the economic burden of healthcare [6]. A multidimensional systems orientation thus has the potential to unveil new modes of thinking that highlight intersectoral relations, communications, collaboration, and cross-boundary learning for improved healthcare performance.

This paper proceeds as follows: we begin by considering a case for change given the numerous stressors in Canadian healthcare systems at present, next, we review existing definitional and conceptual approaches to sustainable healthcare and consider their limitations. We then develop our notion of sustainable healthcare built from an embedded view, and finally consider the implications of that view for healthcare systems management, practice and research.

\section{Methodology}

We looked at the sustainability discourse in the literature over the past decade and analyzed content, focusing on interconnected elements and emerging themes. We identified a lack of unified accepted schemes in evaluating healthcare sustainability and addressed this gap by proposing a framework through the interpretative lens of an embedded systems thinking approach.

\section{Why We Need to Re-Think Healthcare? The Case for Change}

How do we sustain quality healthcare in an era of limited resources and increasing demands? While we, in Canada, spend almost $\$ 200$ billion annually (approximately $12 \%$ of GDP) in healthcare [7,8], we are not achieving optimal health outcomes for the majority of the population. According to a 2012 Conference Board of Canada [9] report, Canada ranked in 10th place out of 17 selected developed countries for health. Japan, Switzerland and Italy were ranked in the top three, the UK placed at 14th, while the United States of America (USA) ranked at 17th. [9]. In 2017, U.S. healthcare spending reached $\$ 3.5$ trillion, with no significant changes in population health. [10]. 
Indeed, as the population ages and healthcare becomes more complex, healthcare costs are expected to continue to rise [9]. Over the last ten years, the growth of healthcare expenditures has surpassed the rate of economic growth in Canada and Statistics Canada estimates that seniors will outnumber children in Canada by a factor of three to two in twenty years' time [11]. Healthcare costs are rising to almost $50 \%$ of provincial government spending budgets. Yet, according to many reports, increased spending in healthcare does not always translate into better health outcomes. As reported by the Organization for Economic Co-operation and Development (OECD) [12], in terms of costs:

"[Canada] rank[s] 7th ... in terms of total health spending per capita-significantly above the OECD average. But Canada is well below average in terms of available per capita resources such as physicians, hospital beds, CT scanners, and MRI units; And Canada's ranking in health outcomes ranges anywhere from 5 th to 25 th for key indicators. For example, Canada ranks 13 th in life expectancy and 8th in mortality due to neoplasms (which include cancer and benign tumors)." [12]

In addition, according to recent reports, Canada has a number of rising diseases with no known cures. Two examples include Inflammatory Bowel Disease (IBD) and Multiple Sclerosis (MS). According to one 2017 report, Canada has one of the highest rates of IBD in the world with approximately 270,000 Canadians living with Crohn's disease or ulcerative colitis [13]. Similarly, according to Statistics Canada in 2018, Canada continues to be the country with the highest rate of MS in the world [14].

Other countries have similar poor correlations between healthcare spending and life expectancy. The OECD found that the USA has the highest healthcare spending per capita and is amongst the countries with the highest paid physicians; however, the USA compares poorly with other countries in rankings on infant mortality, premature mortality and life expectancy [12]. Japan, in comparison, has the lowest healthcare spending per capita, but has one of the highest life expectancies. Japan also ranks higher in other areas. When it comes to technologically-advanced diagnostic medical equipment, such as MRIs and computer tomography (CT) scanners, Japan significantly outperforms other countries [12].

However, technology itself is not a long-term solution. Advancements in technology can improve patient care through better diagnostics and therapies, but are not the driver of creating a healthier population. Technology has its own limitations. Indeed, innovative therapies or revolutionary technologies such as 3D bioprinting bring their own set of ethical, technical and financial challenges which can also act as a barrier for change [15]. Economists think of medical innovation as a valuable but risky good, producing health benefits but increasing financial risk. This perspective overlooks how innovation can lower physical risks borne by healthy patients facing the prospect of future disease [16].

Since healthcare spending is not the key determinant to the health of a population, how do we improve the quality of healthcare in Canada without increasing costs; and how do we make quality healthcare affordable and sustainable for future generations?

\section{What Is Sustainable Healthcare?}

The term sustainability is often associated with preserving the environment while continuing with economic development [17-22]. One of the first definitions was used in the Brundtland Report in 1987 for the United Nations [23]. Sustainable development was defined as the "development that meets the needs of the present without compromising the ability of future generations to meet their own needs." The key idea was that although resources were being used, they also needed to be preserved to meet the needs of future generations. In this context, the sustainability livelihood principle [24] also seems relevant as it is linked with capabilities and livelihoods of individuals with consideration for equity. According to the principle, all forms of resources, namely, natural, physical, economic, and social must be replenished on a regular basis similar to a natural cycle.

In terms of sustainable healthcare, there is no one universal definition [25-28]. Clearly, not all Canadians view sustainable healthcare in the same way. While some want to maintain the status 
quo to the existing system; others recognize that putting more resources into the same system, and doing things the same way, is not going to translate into improvements. We must explore new and different ways of thinking by examining interdisciplinary models, tools, and methods available to us. For example, a newly developed tool, the World Risk Index (WRI) [29], assesses risk and vulnerability on a global scale and is able to demonstrate that focusing on coping capacity and adaptive capacity at the individual and community levels improves all aspects of a system's well-being, including health. The WRI framework uses 23 indicators wherein public and private health expenditure, quality of water sources available to the population, and social networks (neighbourhood, family and self-help) play key roles in determining the Vulnerability Index for 173 countries. Although Canada scores well in the measure of this vulnerability index, the exact proportion of the health-related indicators is not clearly known. An application of this concept is discussed later in this paper with emphasis in identifying risks with a notion of prevention rather than response.

A deeper understanding of sustainable healthcare may be captured by The Canadian Alliance for Sustainable Healthcare (CASHC) [30] which defines sustainable health and healthcare as:

"the appropriate balance between the cultural, social, and economic environments designed to meet the health and [healthcare] needs of individuals and the population (From health promotion and disease prevention to restoring health and supporting end of life) and that leads to optimal health and healthcare outcomes without compromising the outcomes and the ability of future generations to meet their own health and healthcare needs." [30]

According to the CASHC, in order to achieve sustainable healthcare, four guiding principles must be present: accountability for results, value for money, fair and timely access, and appropriateness. Accountability for results is needed to drive improvements in the system, to identify targets and outcomes at all levels and to align accreditation and funding. Value for money involves identifying and eliminating waste, searching for efficiency gains, promoting innovation and improving system performance while achieving health outcomes. The World Health Organization [31] estimates that between 20 to 40 per cent of resources spent on health are lost due to inefficiencies related to medical errors, lack of quality care, inappropriate hospital admissions (and lengths of stay), inadequate staff mixes, and inappropriate drug assignments. Fair and timely access refers to need and priority for Canadians. A lack of fair and timely access not only affects the health of the population, but it can also undermine public confidence in the system. Appropriateness is needed to assess what are the most effective resources to achieve optimal health outcomes.

In addition, six factors [30] are deemed necessary to support sustainable health and healthcare. These include the following:

- Effective disease prevention and health promotion

- Effective health and healthcare systems

- Funding models that drive desired behavioural change

- Leveraging innovation and innovative technologies

- Optimal development, alignment and support of human resources

- Strategic alignment with determinants of health

Although the CASHC model of sustainable healthcare aims at comprehensiveness by spanning numerous dimensions, it does not correspond closely to standard general definitions of sustainability—or sustainable development. Notably absent from the CASHC model is any mention of the natural environment despite the obvious reality that human health is fundamentally predicated on the health of natural systems. Furthermore, we see some of the basic tensions that exist within current healthcare systems built into this definition of sustainable healthcare. For example, the notion that innovation is driven primarily through technological advancement can be at odds with the funding realities facing healthcare, given the enormous costs associated with developing advanced treatment procedures and pharmaceuticals. Overall, it is unclear if this model is sufficient to meaningfully redirect healthcare activities towards improvement and systems-level sustainability. 
Instead, we see greater potential in the recent work of Bhaskaran et al. [3] to define sustainable healthcare as a function of economic, social, and ecological factors. Not only does this definition more closely align with general sustainability models, but it has the potential to stimulate 'out of the box' thinking that challenges status quo assumptions about the role and practice of healthcare in society. In particular, we believe that efforts to advance healthcare sustainability must be based on the observed reality that health systems are embedded within larger social systems, which are themselves embedded within natural ecological systems [5]. This embedded view highlights hierarchical dependencies at the systems level, the most immediate implication of which is that healthcare sustainability is entirely dependent on the health and viability of the larger social and environmental systems within which health systems are nested. Protecting and enhancing the integrity of nature's air, water, land and ecosystems is thus the most basic requirement towards advancing a sustainable healthcare model.

Without a healthy natural environment, is quality food even possible? From an ecological system, our food moves through an agricultural system, distribution system, storage system and factory-processing system that has its own complexities. Any of these systems can fail, resulting in a health outbreak. A most recent example is the reporting of the E. Coli infections linked to romaine lettuce from the central coastal growing regions in northern and central California, resulting in the hospitalization of 62 cases of E. Coli illness in 16 states in the United States and 29 cases in Canada [32].

The relationship between food, nutrition and health continues to be widely debated. Newer diets and beliefs about health have begun a dialogue about which foods lead to better health. For example, proponents of the ketogenic diet, which promotes a high fat, low carbohydrate diet, contend a low carbohydrate diet can reduce inflammation (influenced by sugar, white flour and starches) which may help prevent many chronic diseases. This ground-up perspective beginning with a natural ecological system helps to reframe basic healthcare objectives and leads to a line of questioning that is not currently well represented in mainstream health discourse. For example, how might health systems not only minimize environmental impacts, but more proactively, advance ecological integrity through operational and educational activities? How might health systems promote not only individual-level health outcomes through effective treatment of illness, but the broader well-being and even flourishing [4] of interconnected and interdependent individuals and communities within their specific environmental context? How might simple and effective innovation, founded around the concept of healthy living make a difference in addressing some of the root causes of various ailments? More generally, how can healthcare system sustainability advance so as to meaningfully advance the integrity and vitality of the social and environmental systems upon which they are based?

From this perspective, a growing body of research points to the inseparable connection between nature and human health and suggests that a multitude of health challenges stem from our basic disconnect from the natural environment in modern society [6]. For example, re-establishing individual's connection with nature in relatively simple ways such as orienting patient rooms toward green space versus urban infrastructure has been found to significantly reduce recovery times and hospital readmissions and thereby healthcare costs [6]. Canadian research has similarly uncovered important links between nature immersion and general psychological well-being [33]. Community based health promotion is being examined in Australia [34] determining that features of sustainable health practice include effective relationships and partnerships; evidence-based decision making and practice; emphasis on building community capacity; and supportive context for practice. Connection has been made between health and environmental science [35] to show that a useful conceptual understanding of health-program sustainability can be derived from a synthesis of existing conceptual approaches to health-program sustainability and evidence of associated factors, informed by conceptual approaches developed within sustainability science. The study proposes that health-program sustainability is the ultimate manifestation of a complex web of interrelations between health concerns, stakeholders, resources, and actions analogous to an ecosystem. In Europe, as welfare system sustainability is threatened by an ageing population and demise of the extended family, social protection systems are converging, and a healthcare system based on social sustainability, quality of life 
and social co-responsibility seem to provide a viable solution [36]. Given the breadth and strength of these findings, we see great opportunity in this bourgeoning line of inquiry to simultaneously advance ecological, social, and even economic outcomes within healthcare, though substantial barriers to change remain. In fact, sustainable development cannot be advanced through isolated initiatives, but instead requires an integrated approach of social, ecological, and economic aspects of healthcare, as well as managing the tensions and trade-offs in realizing the benefits and opportunities of this approach.

\section{Are There Barriers to Change?}

\subsection{Ideology and Values}

As Canadians, there may be fewer things that distinguish us from our neighbours to the south. While our businesses, culture, and way of life have been strongly influenced by our American counterparts, our publicly-funded healthcare system still remains highly tied to our identity. In spite of this, there is little consensus on what Canadians value in their healthcare system or what its primary goals should be. Some patients view health goals in terms of acute care hospital outcomes, while others are more concerned with how people are serviced and if wait times are reduced. As a country, should we share the same health goals in order to improve health outcomes? The value of healthcare is being discussed by politicians, taxpayers, economists and healthcare professionals and what healthcare means for Canada going forward. In a new era of legalized marijuana, an opioid crisis and other challenges, it is imperative to also find a balance between scientific approach and political engagement [37]. Traditional models of healthcare assume a 'treatment' approach after the illness has already taken place, whereas some experts support a broader perspective to consider the 'wellness' of the population, that is based on a more proactive and preventive approach. It is believed that considering the physical, mental and emotional needs of Canadians before illness occurs, will deliver better health outcomes. Globally, mental health issues continue to be the largest contributor to non-communicable diseases with a lack of "high quality, culturally-sensitive and contextually-appropriate mental healthcare services." [38]

\subsection{Current Healthcare System Model}

Canada's current healthcare system is derived from a model in the 1960s and is not equipped to adapt easily to change. The system contains the physical infrastructure, provider incentives, service delivery models, labour contracts, the flow of information and various other elements. At that time, the system served its purpose and worked well in meeting patient needs. Today, new challenges, such as an aging population, opioid crises, and mental health concerns have left the system ill-equipped to deal with serving individuals in the community. Overlooked needs such as home-bound care and counselling services contribute toward lack of care and must be addressed appropriately and adequately. The use of electronic medical records is another example where Canada's healthcare system has been slow to adapt compared to other countries. [39]

Canada's healthcare system also reflects a culture of dependence on pharmaceutical companies in providing adequate drugs for treating disease and chronic illnesses. Pharmaceutical companies have done little in terms of education and prevention. In addition, the average consumer does not have the knowledge to determine what amount of salt, sugar and additives are healthy? A lack of updated government regulations about 'what is healthy' means Canadians are left to rely on outdated guidelines that do not reflect the new realities that many Canadians are concerned about such as allergies, gastrointestinal issues and food intolerances.

\subsection{Provincial Differences}

Differences between provinces in healthcare coverage have created much confusion and feelings of inequity amongst Canadians about their healthcare system. 
"The Canada Health Act requires only that provinces provide medically necessary hospital and physician services. Beyond these services, decisions must be made about whether the publicly funded health system should pay for the latest cancer drug, spend more on home care, or invest in public health activities." [2].

Over the years, provinces have made different interpretations of what is medically necessary. Healthcare plans across provinces are not identical. Medical coverage, its limits and the type of healthcare available vary from province to province. As such, a medication that is covered in one province may not be covered under another provincial government's healthcare coverage.

\subsection{Lack of Information and Transparency}

Sharing knowledge within the healthcare system has been a concern according to many experts who agree that our healthcare system operates in silos. As a result, we do not share best practices and further knowledge development within the system and across provinces [1]. Certainly, sharing knowledge between healthcare practitioners within the healthcare system can encourage important learning and progress towards positive change.

In addition, availability of information to the public is far from adequate. Do consumers know what is healthy? In recent years, consumers have become more concerned about their health. But do consumers have access to information to make healthy choices? For instance, some activists have been lobbying for greater transparency of nutritional content such as calories, fat, salt and sugar to be available on menus in fast food outlets and restaurants, so consumers can make more informed decisions about their food choices and their health. Governments have been slow to respond to mandating businesses to comply with this regulation. Similarly, customers are also concerned about where their food is coming from. Many packaged foods now have labels such as "imported", but there is no available information on where certain ingredients are imported from and what quality and assurance standards these ingredients are subject to in other countries.

\section{Adopting a Health Risk Based Approach}

Understanding the underlying factors that create vulnerability in the system is imperative for developing a long term and sustainable healthcare system. It would be worthwhile to consult with and adapt core elements from risk assessment frameworks, such as the GE (General Electric) Healthcare [40] and the World Risk Index approach (Table 1). These concepts may provide guidance to a holistic and sustainable healthcare system as illustrated in Table 1 . The idea is to identify exposure and susceptibility in the system and look at what measures are in place toward coping and adaptive capacities in the system in order to achieve an overall assessment of the system. The approach gives a holistic bird's eye view of the components involved and each component then can be broken down into much detailed and workable sub-components to specifically target areas that need attention. The approach also highlights the fact that addressing underlying issues is the only way to achieve a sustainable healthcare system. For example, some of the root causes that are sure to obstruct sustainability and desirable outcomes of the healthcare system are among other things, education, a lack of understanding of diverse populations, and lack of up-to-date information. Additionally, poverty, homelessness, a lack of access to necessities of life, and a lack of coping ability must be understood and addressed to achieve a sustainable healthcare system [29]. 
Table 1. A risk-based framework for a sustainable healthcare system (adapted from Welles and Birkmann [29]).

\begin{tabular}{|c|c|c|c|}
\hline Exposure & Susceptibility & Coping Capacity & Adaptive Capacity \\
\hline $\begin{array}{l}\text { - } \quad \text { Leading causes of death } \\
\text { - } \quad \text { Leading health issues }\end{array}$ & 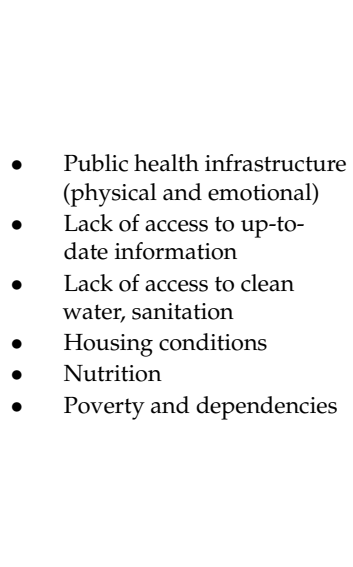 & $\begin{array}{ll}\text { - } & \text { Government- } \\
\text { policy \& decisions } \\
\text { Diverse ethnic and } \\
\text { gender representation } \\
\text { in government } \\
\text { Partnerships } \\
\text { and participation } \\
\text { Early warning } \\
\text { and preparedness- e.g., } \\
\text { ZIKA, SARS, bird flu etc. } \\
\text { - Services-number of } \\
\text { physicians per 10,000 } \\
\text { population, number } \\
\text { of hospital beds per } \\
\text { 10,000 population } \\
\text { Social networks-family, } \\
\text { self-help networks } \\
\text { Insurance or risk } \\
\text { transfer measures }\end{array}$ & $\begin{array}{l}\text { - } \quad \text { Education and research } \\
\text { Gender and ethnic } \\
\text { equity, accommodation, } \\
\text { sensitivity, awareness } \\
\text { Environmental } \\
\text { protection-water resources, } \\
\text { agricultural, } \\
\text { forests, biodiversity } \\
\text { - Investment in prevention } \\
\text { and public health }\end{array}$ \\
\hline
\end{tabular}

\section{Discussion, Limitations and Future Research Directions}

The discussion on achieving a sustainable healthcare system is an ongoing one and there are implications and limitations to certain approaches. Given the inherent within-system stressors and the confluence of broader social and environmental challenges facing society at the global level, sustainable healthcare is a challenge. Sustainability, by definition, can be achieved only when resources are used to achieve outcomes and can be replaced in due course without being irrecoverably depleted. We have attempted to advance beyond the dominant focus on simple economic viability of health systems by considering the broader context within which health systems exist, and by highlighting the constituent elements underpinning health system sustainability.

We have argued that considering health system sustainability as a simple cost reduction activity is unrealistic and we need to understand the multiple relationships between health and its context. In fact, universal health coverage suggests that overall costs do not rise because of increased use of services and healthcare expenditures are not a key determinant of health [41]. Furthermore, healthcare sustainability must take into consideration the understanding of the conditions which shape health and healthcare services, and the ideologies that have motivated particular healthcare reforms within socio-economic systems. Our embedded systems perspective argues that an adequate understanding of healthcare sustainability cannot be derived from separate studies of the individual parts of the system. Emphasis must be put on the larger context and on the interrelationships, taking into consideration socio-economic conditions, government policies, ecology and physical environment; all of which shape the social and environmental determinants of health and thus the demands put on healthcare services.

Canada's report card on healthcare needs to be improved, as expenditures do not match the desired outcomes. Proactive measures such as providing better living environments, food security, childcare and support to marginalized populations can contribute toward a sustainable healthcare system. That is, by spending more on some services, we can reduce the need to spend more on expensive medical conditions. The identification and acknowledgement of health risks will also be a step in the right direction, leading to more prevention measures. Nutrition and calories information on the food served in fast food chains will also add to the sustainability of the Canadian healthcare system in providing information to guide healthy eating. In addition, information sharing is paramount. In a recent CBC (Canadian Broadcasting Corporation) interview [42], Canadian physician and astronaut, Dr. Dave Williams shared his reflections on challenges in the healthcare system based on his tenure as President and CEO of Southlake Regional Health Centre in Ontario, Canada, and his understanding of complex interdependencies. He stated that although challenging, communication and collaboration with multiple diverse providers is vital for improving the system. As well, outcome data, best 
practices, and experiences must be shared across sectors to implement improvements in the system. Through a local community comprehensive partnership model, successful program adaptation and implementation can be accomplished in areas such as mental health, with contextually appropriate services, even in low resource areas [38].

We are hopeful that an embedded systems perspective will stimulate novel and productive approaches toward healthcare sustainability. Demographics are rapidly changing in Canada, and in an age of social media, technological advancements, cultural shifts, and other factors, it is important that the healthcare system leverage innovations into improved health outcomes [43]. Personalized medicine, also referred to as precision medicine, has the potential to improve health outcomes because of its customized approach. Traditional healthcare approaches have used a one-size fits all approach, whereas personalized medicine assumes each individual's health is unique. One scientific advancement that has helped personalize medicine is the availability of genomic information which can assist in predictive care solutions. Cancer is a good example. Collins best explains, "For the same type of cancer, each patient's tumor harbours a unique set of genes driving malignant growth, and that set of drivers often can predict how that particular cancer will respond to therapy." [44]. Another example of personalized medicine is the use of mobile health technologies. Mobile health technologies can be used to provide personalized real-time monitoring of blood pressure, heart rate, diet, exercise and blood chemistries. The potential of these individualized approaches can be used to target treatment more efficiently and accurately, allowing for better prevention and management of chronic diseases such as diabetes. Diabetes is the fastest growing chronic health condition, and is estimated to have cost the Canadian healthcare system 11.7 billion dollars in 2010, with projected costs of 16 billion by 2020. [45].

Finally, investing in research from an embedded system perspective can also address sustainability challenges. A host of research questions, can emerge that can guide future research. For example, how can equity in healthcare be made compatible with economic objectives? how might social systems incorporate mental health needs of vulnerable groups?; under what conditions does economic growth contribute to improved living conditions and "better health for all"? Our framework can be used to analyze how different social, political, economic and environmental dynamics can be linked to minimize risk and optimize population health outcomes. In the end, if we are to achieve health system sustainability, an integrated approach to healthcare is needed, that is embedded in the systems thinking perspective.

Author Contributions: All authors contributed equally on all aspects of the research and in preparation of the manuscript.

Funding: This research received no external funding.

Acknowledgments: We are grateful to the anonymous reviewers who provided their time and valuable comments.

Conflicts of Interest: The authors declare no conflict of interest.

\section{References}

1. Mintzberg, H. Rebalancing Society: Radical Renewal Beyond Left, Right, and Center; Berrett-Koehler Publishers: San Francisco, CA, USA, 2015.

2. UN General Assembly. 2005 World Summit Outcome, Resolution A/60/1, Adopted by the General Assembly on 15 September 2005; United Nations: New York, NY, USA, 2005; p. 38.

3. Baskaran, V.; Shah, B.; Tiessen, A.J. Canada's healthcare sustainability: A holistic perspective on emerging challenges. In Proceedings of the IEEE International Conference on Systems, Man and Cybernetics, San Antonio, TX, USA, 11-14 October 2009; pp. 1453-1457. [CrossRef]

4. Ehrenfeld, J.; Hoffman, A. Flourishing: A Frank Conversation about Sustainability; Stanford Business Books: Stanford, CA, USA, 2013.

5. Marcus, J.; Kurucz, E.C.; Colbert, B.A. Conceptions of the Business-Society-Nature Interface: Implications for Management Scholarship. Bus. Soc. 2010, 49, 402-438. [CrossRef] 
6. Selhub, E.M.; Logan, A.C. Your Brain on Nature: The Science of Nature's Influence on Your Health, Happiness and Vitality; Collins: New York, NY, USA, 2013.

7. Muzyka, D.; Hodgson, G.; Prada, G. The Inconvenient Truths About Canadian Health Care, 2012. Available online: http://www.conferenceboard.ca/cashc/research/2012/inconvenient_truths.aspx (accessed on 14 March 2017).

8. Jaswal, A. Canada 2020 Analytical Commentary No. 3. Valuing Health in Canada. Who, How and How Much? Canada 2020: Ottawa, ON, Canada, 2013; 2p.

9. The CBC. Health Spending. Do Countries Get What They Pay for When It Comes to Healthcare? Conference Board of Canada, 2012. Available online: http:/ / www.conferenceboard.ca/hcp/hot-topics/healthspending. aspx (accessed on 14 March 2017).

10. National Health Expenditure Accounts (NHEA). Available online: https:/ / www.cms.gov/research-statisticsdata-and-systems/statistics-trends-and-reports/nationalhealthexpenddata/nationalhealthaccountshistorical. html (accessed on 3 January 2019).

11. Prada, G.; Grimes, K.; Sklokin, I.; Defining Health and Health Care Sustainability. Defining Health and Health Care Sustainability. The Conference Board of Canada. Report July 2014 Page 6. Available online: http:/ /www. conferenceboard.ca/temp / f98acc1e-a258-4310-828d-1bbf53589730/6269-defininghealth_rpt.pdf (accessed on 15 December 2018).

12. OECD. Health at a Glance 2013: OECD Indicators; OECD Publishing: Paris, France, 2013.

13. Yourex-West, H. Crohn's Disease, Colitis Cases Projected to Rise in Canada: Report, Global News 2018. Available online: https://globalnews.ca/news/4770109/crohns-disease-colitis-rise-canada-report/ (accessed on 12 January 2019).

14. Dubé, D.-E. Brain Interrupted-Multiple Sclerosis in Canada: Understanding Shy MS Rates Are the Highest Here 2018. Available online: https:/ /globalnews.ca/news/4191203/multiple-sclerosis-canadaunderstanding-why-ms-rates-are-the-highest-here/ (accessed on 12 January 2019).

15. Iandolo, F.; Vito, P.; Fulco, I.; Loia, F. From health technology assessment to health technology sustainability. Sustainability 2018, 10, 4748. [CrossRef]

16. Lakdawalla, D.; Malani, A.; Reif, J. The Insurance Value of Medical Innovation; Working Paper 21015; National Bureau of Economic Research: Cambridge, MA, USA, 2015. Available online: http:/ /www.nber.org/papers/ w21015 (accessed on 12 January 2019).

17. Kuhlman, T.; Farrington, J. What is Sustainability? Sustainability 2010, 2, 3436-3448. [CrossRef]

18. Kates, R.W.; Clark, W.C.; Corell, R.; Hall, J.M.; Jaeger, C.C.; Lowe, I.; McCarthy, J.J.; Schellnhuber, H.J.; Bolin, B.; Dickson, N.M.; et al. Sustainability Science. Science 2001, 292, 641-642. [CrossRef] [PubMed]

19. Pfau, S.F.; Hagens, J.E.; Dankbaar, B.; Smits, A.J.M. Visions of sustainability in bioeconomy research. Sustainability 2014, 6, 1222-1249. [CrossRef]

20. Ostrom, E. A General Framework for Analyzing Sustainability of Social-Ecological Systems. Science 2009, 325, 419-422. [CrossRef] [PubMed]

21. Chamber, R.; Conway, G. Sustainable Rural Livelihoods: Practical Concepts for the 21st Century; IDS Discussions Paper \#296; IDS: Brighton, UK, 1992.

22. Barile, S.; Saviano, M. Complexity and Sustainability in Management: Insights from a Systems Perspective. In Social Dynamics in a Systems Perspective; Barile, S., Pellicano, M., Polese, F., Eds.; New Economic Windows; Springer: Cham, Switzerland, 2018.

23. WCED. Report of the World Commission on Environment and Development: Our Common Future 1987. Available online: www.un-documents.net/our-common-future.pdf (accessed on 12 January 2019).

24. Barile, S.; Saviano, M.; Iandolo, F.; Calabrese, M. The viable systems approach and its contribution to the analysis of sustainable business behaviors. Syst. Res. Behav. Sci. 2014, 31, 683-695. [CrossRef]

25. Giovannoni, E.; Fabietti, G. What is sustainability? A review of the concept and its applications. In Integrated Reporting-Concept and Cases that Redefine Corporate Accountability; Busco, C., Frigo, M., Riccaboni, A., Quattrone, P., Eds.; Springer International Publishing: Cham, Switzerland, 2014.

26. Murphy, K. The social pillar of sustainable development: A literature review and framework for policy analysis. Sustain. Sci. Pract. Policy 2012, 8, 15-29. [CrossRef] 
27. Capolongo, S.; Bottero, M.C.; Lettieri, E.; Buffoli, M.; Bellagarda, A.; Birocchi, M.; Cavagliato, E.; Dervishaj, A.; di Noia, M.; Gherardi, G.; et al. Healthcare Sustainability Challenge. In Improving Sustainability During Hospital Design and Operation; Capolongo, S., Bottero, M., Buffoli, M., Lettieri, E., Eds.; Green Energy and Technology; Springer: Cham, Switzerland, 2015.

28. Faezipour, M.; Ferreira, S. Applying systems thinking to assess sustainability in healthcare system of systems. Int. J. Syst. Syst. Eng. 2011, 2, 290-308. [CrossRef]

29. Welle, T.; Birkmann, J. The World Risk Index-An approach to assess risk and vulnerability on a global scale. J. Extrem. Events 2015, 2. [CrossRef]

30. CASHC. Principles of Sustainable Healthcare. The Conference Board of Canada, 2016. Available online: http:/ / www.conferenceboard.ca/cashc/principles.aspx (accessed on 14 March 2017).

31. World Health Organization. Health Systems Financing: The Path to Universal Coverage, 2010. Available online: http:/ / www.who.int/whr/2010/en/ (accessed on 14 March 2017).

32. Outbreak of E. coli infections linked to romaine lettuce. Am. J. Transplant. 2018, 19, 291-293. [CrossRef]

33. Nisbet, E. Happiness is in our Nature: Exploring Nature Relatedness as a Contributor to Subjective Well-Being. J. Happiness Stud. 2011, 12, 303-322. [CrossRef]

34. Harris, N.; Sandor, M. Defining sustainable practice in community-based health promotion: A Delphi study of practitioner perspectives. Health Promot. J. Aust. 2013, 24, 53-60. [CrossRef] [PubMed]

35. Gruen, R.L.; Elliott, J.H.; Nolan, M.L.; Lawto, P.D.; Parkhill, A.; McLaren, C.J.; Lavis, J.N. Sustainability science: An integrated approach for health-programme planning. Lancet 2008, 372, 1579-1589. [CrossRef]

36. Garcés, J.; Ródenas, F.; Sanjosé, V. Towards a new welfare state: The social sustainability principle and healthcare strategies. Health Policy 2003, 65, 201-215. [CrossRef]

37. Blanchet, K.; Girois, S. Selection of sustainability indicators for health services in challenging environments: Balancing scientific approach with political engagement. Eval. Program Plan. 2012, 38, 28-32. [CrossRef] [PubMed]

38. Stirman, S.W.; Kimberly, J.; Cook, N.; Calloway, A.; Castro, F.; Charns, M. The sustainability of new programs and innovations: A review of the empirical literature and recommendations for future research. Implement. Sci. 2012, 7, 17. [CrossRef]

39. Acharya, B.; Maru, D.; Schwarz, R.; Citrin, D.; Tenpa, J.; Hirachan, S.; Basnet, M.; Thapa, P.; Swar, S.; Halliday, S.; et al. Partnerships in mental healthcare service delivery in low-resource settings: Developing an innovative network in rural Nepal. Glob. Health 2017, 13, 2. [CrossRef]

40. Abbam, G. Achieving Affordable and Sustainable Healthcare; GE Healthcare, Health Government Affairs and Policy: Buckinghamshire, UK, 2015; 24p.

41. Lu, R.J.-F.; Hsiao, W.C. Does Universal Health Insurance Make Health Care Unaffordable? Lessons from Taiwan. Health Affairs 2003, 22, 77-88. [CrossRef]

42. Astronaut and ER Doctor Dave Williams on Success and Setbacks, CBC White Coat Black Art with Dr. Brian Goldman, 3 January 2019. Available online: https://www.cbc.ca/listen/shows/white-coatblack-art/episode/15659403 (accessed on 3 January 2019).

43. Dougherty, D.; Conway, P.H. The "3T's" Road Map to Transform US Health Care The "How" of High-Quality Care. JAMA 2008, 299, 2319-2321. [CrossRef]

44. Collins, F.S. Exceptional Opportunities in Medical Science: A View from the National Institutes of Health. JAMA 2015, 313, 131-132. [CrossRef] [PubMed]

45. Statistics Canada. Canadian Community Health Survey; Statistics Canada: Ottawa, ON, Canada, 2014.

(C) 2019 by the authors. Licensee MDPI, Basel, Switzerland. This article is an open access article distributed under the terms and conditions of the Creative Commons Attribution (CC BY) license (http://creativecommons.org/licenses/by/4.0/). 